\title{
MOBILE TECHNOLOGY CULTURE AND ITS IMPACT ON COLLEGE STUDENTS' LOCAL NEWS VIEWING BEHAVIOR
}

\author{
Jennifer Breese-Vitelli, Lasell College,jbreesevitelli@lasell.edu \\ Debra J. Borkovich, Robert Morris University,borkovich@rmu.edu
}

\begin{abstract}
The ways we receive and the sources we rely on to deliver the news are changing. The main interface for local news consumption is beginning to shift toward mobile devices. However, the Pew American Life Project (2011) pointed out that among the adults that do use a mobile device to view local news, viewing behavior has shown that there is not one group that produces a distinct pattern of viewing behavior, but many. The older segment of the age-range titled 'adult' could have a negative technological bias that does exist in future generations sometimes referred to as 'digital natives.' This quantitative research focused on a sample of college-aged students on their mobile device viewing behavior in an attempt to identify patterns, as they may have many long run implications for the future of news media outlets and cultural differences in technology usage behavior.
\end{abstract}

Keywords: Mobile Technology, Social Media, Mobile Devices and Technology

\section{INTRODUCTION}

The ways we receive and the sources we rely on to deliver the news are changing exponentially; and the main interface for local news consumption is beginning to shift toward mobile devices [27]. However, the 2011 Pew American Life Project pointed out that among the adults that do use a mobile device to view local news, viewing behavior has shown that there is not one group that produces a distinct pattern of viewing behavior, but many [19]. Beyond the influx of personal email, instant and text messages, the web increasingly supplies us with all manner of other automated notifications. We are alerted by feed readers and news aggregators whenever a news story appears at a favorite publication or on YouTube. Social media alerts us to what our friends are doing, often moment by moment, telling us whenever one of the people we "follow" broadcasts a new message. Depending on how many information streams we subscribe to and the frequency of the updates, we may field a dozen news alerts per hour, and for some, the number may be higher. News, breaking or otherwise, is a powerful distraction, and electronic transmissions provide that instant gratification and assurance that we are infinitely wired-in, no longer impatiently waiting for that final commercial to end prior to the cable broadcast or standing by for the next edition of our favorite daily newspaper. Carr [7, p. 88] reminded us that: "Once the information is digitized, the boundaries between media dissolve," and therefore our time reading print publications, such as newspapers and magazines, and watching television news broadcasts steadily decreased in favor of the latest and greatest technology available.

Navigating the web for current, accurate, and complete news sources requires proficient and efficient dedication to multitasking with the ability to quickly scan and comprehend items of interest, and the willingness to abandon or discard others as nonessential and move on. Unfortunately, supplying information in more than one form or format concurrently may take a toll on understanding or remembering content. To illustrate this systemic media distraction, Cornell researchers studied two groups of college students in a lecture environment where one group was permitted to access the web at will for news and other information during class time. Not surprisingly, results indicated that the web surfing students performed poorly on immediate measures of memory for the lecture content, regardless of whether or not their web surfs were related or unrelated to the lecture subject matter [14].

The 2011 Pew American Life Project determined while adults do not produce a distinct pattern of viewing behavior, they are more likely to use a mobile software program or application ("app") to retrieve local news; however, because the age group encompassed in the definition of adult was very broad it examined whether traditional college-aged students differ in this growing technological age [19]. It was discovered that the older segment of the age-range segmented as 'adult' had a technological bias that did not exist in future generations. To explore this, college-aged students were sampled on their viewing behavior, as they were the first generation to grow up in a completely technologically saturated world. Patterns were identified in their behavior, such as the need for 
convenience, speed, and proximity, that may have many long run implications for news media outlets in the future as they may provide a firm grasp on what types of media need to be marketed to which age groups, which forms of media eventually might need to be phased out, and which need to be developed to meet the needs of future generations. Nevertheless, these economic and marketing statements tie directly to McLuhan's [18, p. 7] aphorism, "the medium is the message," asserting that we are conditioned to accept communications technologies as socialcultural constructs and extensions of ourselves.

The goal of this research was to explore four phenomena. The first was whether students' use of mobile computing devices such as smart phones, iPods, tablets, and other like technologies had an impact on how students consume local and national news. The second was to identify if distinct patterns existed among a college-aged population. The third was to determine if habit forming behavior suggested by Diddi and LaRose [10], caused the population to seek out traditional forms of media as a source for news, and potentially be replaced with new habits produced by a younger generation of news seekers with access to more advanced forms of media. Lastly, the study explored whether college-aged students valued news enough to pay for it and in what delivery mode.

This research also provided data to explore the definition of local media with regard to the geographic location of the students viewing it. As many students leave the region that they are from to attend secondary educational institutions, it was important to determine if they viewed the local news of the region they are from or the region they currently inhabit, and if distance from their community of origin had any effect on their desire to view local news. For instance, some college students construed local news as automatic emails, text messages, and voice mails from on-campus alert systems. Following a 2007 mass shooting incident at Virginia Tech that left 32 people dead and 17 injured, amendments to the US Federal Higher Education Opportunity Act of 2008 required colleges and universities to establish emergency notification systems using any and all technological advancements readily available [30]. This information indicated that student behavior with regard to local news may not be correlated only with the technological mediums available to view it, but with the physical proximity of the student to what they would consider to be their local news. As patterns were identified among college students that move to other geographic locations for their studies, and for the sole purposes of this study, this research further determined the meaning of local news for the subject students. Therefore, this research also centered on whether the students were more inclined to view the local news in their new location if they felt they had adopted that community as their own and moved their permanent residence accordingly, or were more inclined to continue to view the local news of their hometown if they still had family or a permanent residence there.

This study also focused on the social-cultural issues that drive students to accept virtual realities and digital tools as their primary sources of local news and information. Sociologists, anthropologists, social psychologists, and other subject matter experts argue that technology environments encourage avid participation of young adults into a virtual world completely reliant and trusting of the digital information received, with little or no challenge to its currency, accuracy, or completeness. Not all virtual news sources are under the journalistic legal and editorial constraints and restraints of the fourth estate (press), and college-aged students and other young adults are more likely to trust their instant digital sources rather than verify. The next section explores the arguments of subject matter experts to ascertain how students define the social-cultural construct of "news," and why they are drawn to these applications for news and current events.

\section{BACKGROUND AND IMPLICATIONS (LITERATURE REVIEW)}

According to the 2011 Pew Center's Internet and American Life Project local news is going mobile. Nearly half $(47 \%)$ of all respondents reported that they get at least some local news and information on their mobile computing device (cellphone, PDA, or tablet computer). Along with the proliferation of mobile computing devices are the mobile software programs, also known as "apps." Figures 1, 2, and 3 depict 2012 Pew data [17] that clearly illustrate the increasing rise of digital news consumed compared to the steady decline of news accessed via newspapers, television, and radio, respectively. 


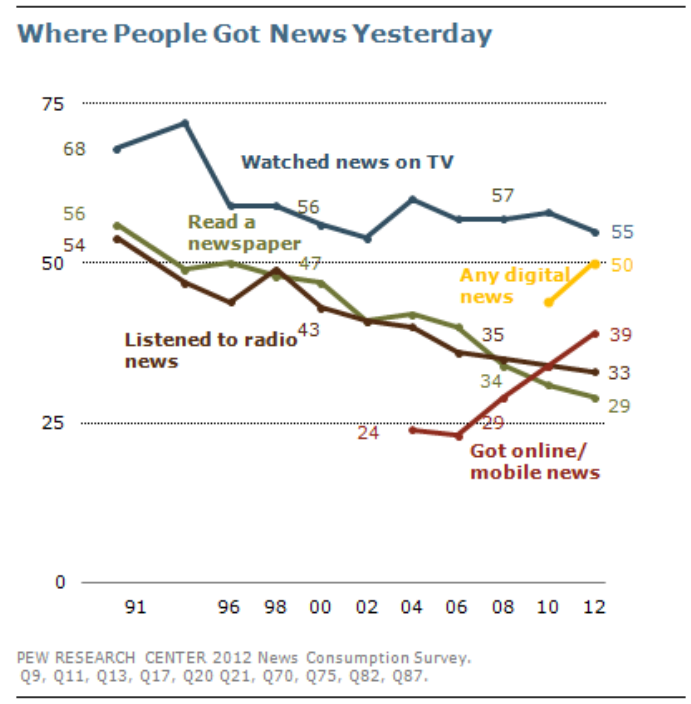

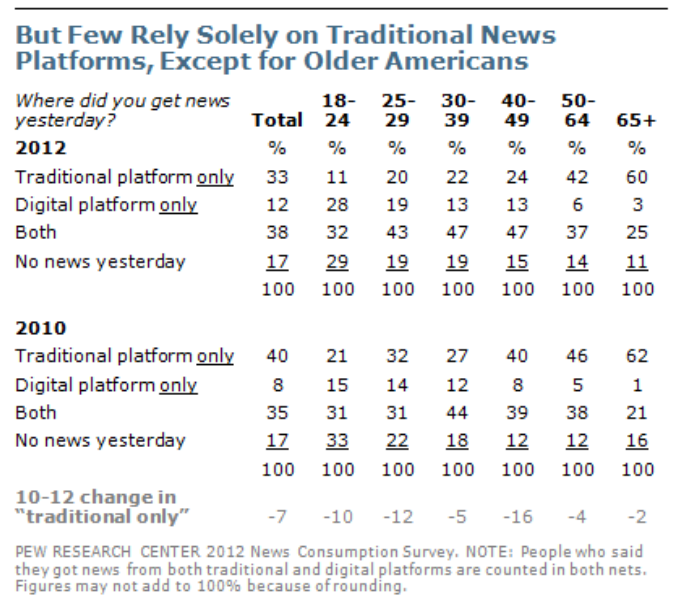

Figure 2. Statistical sources of news [17]

Figure 1. Rise of digital news; decline of other sources [17]

\begin{tabular}{|c|c|c|c|}
\hline \multicolumn{4}{|c|}{$\begin{array}{l}\text { Just a Third of Young People } \\
\text { Watched Any TV News Yesterday }\end{array}$} \\
\hline $\begin{array}{l}\text { Watched news on } \\
\text { television yesterday ... }\end{array}$ & $\begin{array}{c}2006 \\
\%\end{array}$ & 2012 & Change \\
\hline Total & 57 & 55 & -2 \\
\hline $18-29$ & 49 & 34 & -15 \\
\hline $30-49$ & 53 & 52 & -1 \\
\hline $50-64$ & 63 & 65 & +2 \\
\hline $65+$ & 69 & 73 & +4 \\
\hline
\end{tabular}

PEW RESEARECH CENTER 2012 NCWS Consumption Survey. Q13.

Figure 3. Young adults steadily drift away from TV news [17]

There have been numerous studies on how students use technology. Parker and Plank [20] highlighted new media consumption and the growing medium of the internet as an information source. Stroud [29] investigated whether the type of media being used is at all correlated with the propensity for one to be selective in their news exposure. But do these new technologies really make it easier for individuals to find news that matches their political and social beliefs? If this is the case and technology makes targeted media more effective, then as Carr [7] suggested, perhaps news mediums such as National Public Radio (NPR) which are not overtly political and lack an acceptable degree of cost-effectiveness are doomed to be replaced by targeted technological news media aimed at a specific but smaller group of followers. The group in this instance could afford to be smaller while maintaining a greater amount of costeffectiveness due to a significant decrease in production costs, but also because those who currently consume media on a mobile device are twice as likely to agree to pay to access mobile news as those who consume traditional media. Those who consume news on mobile devices are more likely to see value in the news they consume and pay for the convenience to continue to view it on a mobile device [27]. These studies provided a basis for measuring and determining if mobile technology use has any effect on the consumption of local news on a mobile device versus viewing the news using standard media as a medium. 


\section{"News" Defined}

Students' perception of the term "news" resulted in several interpretations. Postman [24; 25] described the culture of news as "television dominated by entertainment values . . . and crowded out by the discontinuities of programming that is interrupted every 12 minutes for commercial messages." Batteau [1] asserted that the advent of cable in the late $20^{\text {th }}$ century propelled the selling of news, regardless of the medium, and news quickly became the selling of culture 365/7/24. Batteau [1, p. 119] further insisted that visually-driven Americans, fueled by the internet explosion of graphic-interfaces and the eventual computer in every lap and smartphone on every hip "replaced the culture of orality and the culture of literacy." By the mid-1990s, messages and images were communicated globally within seconds and virtual acceptance of cyber technology was instantaneous. Global news, regional news, local news, and campus news were so widely accessible that Americans no longer had prudent, reasonable, or rationale excuses to support a lack of information. But what type of information did they access? And do students merely read the headlines and move on? Do they further search for more in-depth data and do they bother to check a second source to verify the information?

Technology 2.0 has taken the world into a virtual reality where ubiquitous internet participation is advocated and welcomed. The media encourages college students and adults to share, report, collaborate, and upload news on websites. Information is streaming live at break-neck speed with little regulation or oversight, and a vast opportunity exists to post subjective opinions in lieu of objective news. Postman [25, p. 70] described e-news as "information appear[ing] indiscriminately, directed at no one in particular, in enormous volume and at high speeds, and disconnected from theory, meaning, or purpose." Batteau [1, p. 123] questioned "whether technological literacy has sufficient widespread diffusion to permit the emerging community to control the course of Web 2.0 or whether its control will pass out of the hands of nerds and lobbyists [and marketers] and into the corporate [and political] realm [virtually unchecked]." These decisions will be left to the halls of Congress and corporate boardrooms, but hopefully, not without input from the informed electorate and consumers of news. Postman [25, p. 16] proffered that "new technologies compete with old ones - for time, for attention, for money, for prestige, but mostly for the dominance of their worldview." In its quest for college student market-share, the news media, fueled by the $21^{\text {st }}$ century ambitions of the fourth estate, are no less aggressive and volatile. The media are well-aware that college students are the high-energy, fast-paced, rapid-response earners and consumers of the future.

\section{Digital Native vs. Digital Immigrant}

The term "digital native" introduced by Prensky [26] argued that today's youth, college students, and other young adults born into the Information Age spend their lives surrounded by technology, using computers, videogames, mobile computing devices, and all the toys and tools of the digital age. Prensky [26] further asserted that those not born into the virtual world, but have learned to adapt to the environment and to a certain extent adopt the technology, are known as "digital immigrants."

Other subject matter experts [2] vehemently disagreed with this tack, arguing that Prensky's metaphors generalized and marginalized both the roles of native and immigrant. Bayne and Ross [2] purported that Prensky lumped together all natives, regardless of gender, race, background, ethnicity, homeland, and cultural differences, presuming all were like-minded; and that all immigrants were akin to the biased $19^{\text {th }}$ and $20^{\text {th }}$ century stereotypes of heavily accented unintelligible foreigners. Selwyn [21] agreed that the terms digital natives and immigrants were too generic and did not speak to the true social-cultural aspects of individuals whose day to day lives, patterns, and habits also participated in elements of a very non-technological environment of personal networks consisting of family, friends, schools, community contacts, print and other mass media sources for news. Selwyn [28, p. 364] found that young adults' use of digital technologies were often varied and unspectacular, asserting that the term digital native "highlights a misplaced technological and biological determinism." Carr [7, p. 227] further argued that the effects of digital media cannot be described in generational terms and that "such distinctions strike me as misleading, if not specious. . . . Net culture is not youth culture; it's mainstream culture." 
Nevertheless, those "digital immigrants" born prior to the mid-1980s [9] were less likely to rely on "app" sources for complete news and current events, but are more likely to scan digital headlines and opening sentences to stay informed, and then pursue other sources, such as television, radio, and print media for more detailed, descriptive, and complete information. "Digital natives" are more confident of virtual news sources, prefer snapshots and sound bites of data, and rarely pursue deeper context and longer passages to read unless a specific instance or need requires further scrutiny [22]. "It is now clear that as a result of this ubiquitous environment and the sheer volume of their interaction with it, today's students think and process information fundamentally different from their predecessors" [26, p. 1]. But does this student confidence in digital news sources reflect a quiet trust or an immature naïveté?

\section{Socio-Technical Applications of Digital Systems: Trust vs. Naïveté}

A culture based upon openness, trust, respect, collaboration, shared meanings, and resources reflects a mutual understanding of goals, objectives and purpose, but how are these values and mission applied to "group-think" in a techno-virtual environment? In the $21^{\text {st }}$ century, technology and culture do not lead separate lives, but are implicitly and explicitly intimately connected and linked by communities of practice, semiotics, signs, cues, and coded and decoded language (English, digital, and/or otherwise). The socio-technical theory [4] describes the interaction between people and technology in the workplace and social informatics [16] provides the tools of the interface.

Technology and culture tend to evoke dramatically different connotations, systems of meaning, experiences, and worldviews. Among today's youth, college students, and many young adults: "Technology is clean, powerful, exciting and a magical key to prosperity" [1, p. 1]. As naïve as this statement may be, some believe there are no problems that cannot be solved without some form of technology. Technophiles [25] and early adopters [5;6] argue that technology represents a necessary upheaval, innovation, and creative destruction to the permanence and stability of organizational, societal, and national culture.

Alternatively, culture is traditionally interpreted by the masses as the visible and tangible "fine arts" of music, dance, drama, painting, philosophy, etc., a lifetime achievement reserved for the cultivated elite [1]. But social scientists, such as anthropologists and sociologists, view both the tangible and intangible learned systems of shared understandings, patterns of behavior, rules, rituals, traditions, language, heroes, symbols, etc. as the glue that binds like-minded humans organized in formal and informal groups, communities, and societies [13; 15]. Crain [8] describes this milieu as "groupiness," where people access and read digital news and other social media mainly to experience a feeling of belonging rather than for personal enlightenment or amusement. Since electronic text is impermanent, revisions of digital news can be infinite thereby diminishing the pressure to achieve publication perfection [7]. The digital readers' reliance on and pleasure in informal and immediate access to news is based upon the perception that online news can be continually edited, updated, and enhanced; therefore encouraging an uncritical trust of media sprinkled with the naïveté that news editors will diligently and ethically take the time to correct items rather than moving on to the next headline.

\section{American Obsession with Scarcity of Time and Workarounds}

The ancient Greek philosopher, Seneca [c. 4 BC - 65 AD], argued that "Time is our most scarce resource," and although adults embrace this adage and fervently wish for more time, college students unwittingly live it. Today's students are used to the instant gratification of social media, hypertexting, downloaded music, smartphones, laptop libraries, global positioning systems (GPS), e-games, e-commerce, e-banking, e-scheduling, e-dating, instant messaging, and more. If a PC, smartphone, or e-library web search experiences a transmission delay or some other IT malfunction, the on-hand lack of media provokes an instant response often resulting in student 'workarounds' [23]. For example, students are creative, innovative and impatient, and if they cannot access an information system, or are frustrated at the rate of response, or just do not know how or what to do, they often implement technical 'workarounds.' Petrides, McClelland, and Modine [23, p. 100] described 'workarounds' as 'informal practices ... idiosyncratic methods of data collection and management . . . both inventive solutions to pressing organizational needs, and over time, costly alternatives to a robust and flexible information system." 'Workarounds' allude to students' use of mobile "apps," and various social media such as WIKIs, YouTube, Facebook, Twitter, and others for sources of news and related information often without checks for reliability, credibility, and accuracy. The 
authors' research clearly inferred that students are willing to accept the risks associated with lack of data confirmation when seeking breaking news from social media.

\section{Pilot Study of Social Media Usage by Business College Students for News Gathering}

In 2011, a pilot study performed by Perez-Caballo and Balszczynski [21] surveyed 126 business students enrolled in a Western university regarding their use of social media, including news gathering practices. Surprisingly, the results obtained in this pilot study were interesting and mixed as the general use of the internet for news was in line with the 2011 Pew Study; but the reliability and worthiness of news obtained from social media was in direct conflict with other subject matter experts who reported that college students generally accepted social media news information without question or confirmation. Perez-Caballo and Balszczynski [21] reported that men preferred Twitter and women preferred Facebook for information gathering; both genders were interested in seeking international, business, science, and US politics news; men preferred sports news; and women sought entertainment and arts news more frequently. A significant number of the sample study (78\%) preferred the internet as a news source; however, a large portion of those surveyed (72.2\%) admitted to never using Twitter. The pièce de résistance or highlight of the findings was: "We found that our subjects considered the new social media unreliable and unworthy of their time. They did not seem to think that they could find valuable information as a result of using Twitter or Facebook" [21, p. 8].

Based upon the prior research of social scientists and other subject matter experts, there is a clear need for more research and serious study of college students, their access to technology to gather hard and soft news, and the influences and implications of their social-cultural environments on and off campus, hometown, regional, national, and global. This study explored how college students used mobile computing devices such as smart phones, iPods, tablets, and other like technologies to consume local and national news; if distinct patterns existed among a collegeaged population; if habit forming behavior caused the population to seek out traditional forms of media as a source for news; and whether college-aged students valued news enough to pay for it and in what delivery mode. The following sections describe the research methodology and how it was implemented, the data analysis, results, findings, conclusion and implications for future research.

\section{RESEARCH METHODOLOGY}

This was a quantitative study and its approach to inquiry provided the ability to draw generalizations about the population by taking a sample of that population and formulating claims based on the results. Similarly, a larger population was reviewed at a single point in time through the use of quantitative methods. The intended consequence of the population comparisons was to show statistically significant relationships reflecting a pattern rather than chance.

\section{Research Design}

The survey instrument for this study was developed by the 2011 Pew American Life Project [27] to determine which methods are being chosen to consume news. The population in the Pew study varied, but the population of this study focused on current college students in both Massachusetts and Georgia. The section of the Pew Survey [27] used was a 26 question survey that specifically addressed how this population consumes their local news. Some demographic questions were added for additional analysis, comparison, and segmentation. The survey was administered through a link developed with Survey Monkey. The results were analyzed using SPSS and compared to the Pew results [27].

\section{DATA ANALYSIS AND RESULTS}

Data analysis performed was based on a spreadsheet containing responses from participants. The spreadsheet was downloaded from Survey Monkey in an Excel format, coded and uploaded into SPSS for comparison. Additionally, an extensive review of the literature assisted in developing an explanation to determine whether a relationship existed between the varying age populations and their news viewing behavior. 
A total of 107 survey responses were gathered between October of 2012 and May 2013. The goal was to survey "traditional" college students who attended at age 18 directly after high-school, but with the trend of college students returning to finish their education later, going part-time due to family obligations, and transferring from other schools and programs, the age of the respondents attending college was older than originally expected. All of the survey respondents were college students; however the analysis collapsed the participants into two age groups 18-24 or "traditional" and 25+ for the "non-traditional" college students. The data was analyzed comparing the two groups to each other and the overall survey population to the 2011 Pew Study [14]. Despite the majority of responses coming from the School of Information Sciences (52\%) followed by the School of Business (16\%) gender responses were almost completely even. The inquiry of the four research questions uncovered some surprising results and others that need additional research.

RQ1: Do students' use of mobile computing devices such as smart phones, iPods, tablets, and other like technologies have an impact on how they consume local and national news? Table 1 depicts (via percentages and age groups) how mobile users obtain each type of information.

Table 1. Use of Mobile Device - Yes (Often)

\section{Percent (\%) of mobile users in each age group getting each type of information}

\begin{tabular}{|c|c|c|c|c|}
\hline Types of Information & All & $18-24$ & $25+$ & $\begin{array}{l}\text { Other } \\
\text { PEW }\end{array}$ \\
\hline $\begin{array}{l}\text { Go online for information or news about your local } \\
\text { community }\end{array}$ & $44.4 \%$ & $43.3 \%$ & $46.2 \%$ & $30.0 \%$ \\
\hline Get information about local traffic or public transportation & $34.3 \%$ & $38.3 \%$ & $28.2 \%$ & $22.0 \%$ \\
\hline Check local sports scores or get local sports updates & $35.4 \%$ & $31.7 \%$ & $41.0 \%$ & $24.0 \%$ \\
\hline Check local weather reports & $64.9 \%$ & $61.0 \%$ & $71.1 \%$ & $42.0 \%$ \\
\hline Find local restaurants or other local businesses & $51.5 \%$ & $46.7 \%$ & $59.0 \%$ & $37.0 \%$ \\
\hline $\begin{array}{l}\text { Get or use coupons or discounts from local stores or } \\
\text { businesses }\end{array}$ & $32.3 \%$ & $23.3 \%$ & $46.2 \%$ & $19.0 \%$ \\
\hline $\mathrm{N}=$ & 99 & 60 & 39 & 1,965 \\
\hline
\end{tabular}

Respondents who answered yes (often) from the student population must be getting their news from others sources; overall only (17\%) of those surveyed have a paid subscription for delivery of an actual newspaper compared to (30\%) of the Pew study. Comparing only the 18-24 year olds to the non-traditional student participants (25+), the rates $(19 \%)$ and $(15 \%)$ respectively were not significant. However, the coupon usage of the mobile devices stood out from the other question where (23\%) of the 18-24 year-olds compared to $(25+)$ year olds $(46 \%)$ used the devices for purposes of coupons or discounts from local businesses compared to only (19\%) of the Pew study which could loosely fit the definition of local news. Of the (99\%) combined participants who had a capable device (65\%) are using the device to access weather compared to the (42\%) of the Pew study. Combined participants (44\%) go online for information or news about their local community compared to (30\%) reported by Pew.

RQ2: Were there distinct patterns of viewing behavior among a college-aged population?

While a specific question was added to the survey to address patterns asking the students to define their definition of "local" uncovered differences between what the students determined "local" to mean: being wherever they are at the current time, their hometown, and where they currently reside. However, distinct patterns of viewing behavior based on their understanding of local could not be determined. The limited population could not be compared to the students' year in college or whether they were urban, rural, or suburban which was expected to differ among those respondents. Additional research in the future comparing other colleges geographically and adding social media behavior is expected to provide additional answer to this question. However the population is more likely to have a 
mobile application, less likely to have an actual delivery of a physical paper, more likely to have news emails and texts "pushed" or sent to them, and less likely to be impacted if there were no local news paper available than the respondents of Pew study.

RQ3: Does habit forming behavior cause the population to seek out traditional forms of media as a source for news, and be replaced with new habits produced by a younger generation of news seekers with access to more advanced forms of media?

Because the frequency by which these applications are accessed was not uncovered by the questions it is difficult to determine whether or not the younger generation does indeed have specific viewing patterns; however, due to the fact that college students regardless of age seemed to have similar viewing behaviors differing from the overall Pew study. Only (17\%) of the college population answered that they pay for the delivery of an actual paper while (33\%) of the Pew study answered yes to the same question.

RQ4: Do college-aged students value news enough to pay for it and in what delivery mode?

There was no statistical significance between all of the populations responding they were willing to pay $\$ 5$ for an online news service. For the traditional student population (18-24), a little over $(20 \%)$ of them would be willing to pay $\$ 5$ for an online service. Of those paying in the college populations, half are paying because a physical paper is not available. For those not willing to pay, two thirds of them just would pay while the other third would not pay because no online version exists- However, approximately (46\%) do have an "app" that allows access to local news with about (84\%) compared to the (99\%) not willing to pay for such "app" in the Pew study. Finally, only (8\%) of overall college student respondents expressed a major concern if there local paper no longer existed whereas (28\%) of the Pew study expressed the same concern.

Tables 5, 6, 7, and 8 illustrate, via percentages and age groups, the responses to RQs 2, 3, and 4 .

Table 5. Pay for physical delivery of paper

\begin{tabular}{|c|c|c|c|c|}
\hline Percent in each age group & & & & \\
\hline & All & $18-24$ & $25+$ & Other PEW \\
\hline Pay for Physical Delivery of Paper & $17.3 \%$ & $18.6 \%$ & $15.4 \%$ & $33.0 \%$ \\
\hline $\mathrm{N}=$ & 98 & 59 & 39 & 2,251 \\
\hline
\end{tabular}

Table 6. Impact of no local paper

\begin{tabular}{lllll}
\hline Percentage in each age group & All & $\mathbf{1 8 - 2 4}$ & $\mathbf{2 5 +}$ & Other PEW \\
\hline Don't Know & & & & $0.0 \%$ \\
Major Impact & $0.9 \%$ & $0.0 \%$ & $2.4 \%$ & $28.0 \%$ \\
Minor Impact & $8.4 \%$ & $12.3 \%$ & $2.4 \%$ & $30.0 \%$ \\
No Impact & $33.6 \%$ & $35.4 \%$ & $31.0 \%$ & $39.0 \%$ \\
N= & $57.0 \%$ & $52.3 \%$ & $64.3 \%$ & $\mathbf{2 , 2 5 1}$ \\
\hline
\end{tabular}

Table 7. Have "apps" for news or local information

\begin{tabular}{ccccc}
\hline & All & $\mathbf{1 8 - 2 4}$ & $25+$ & Other PEW \\
\hline Yes & $45.9 \%$ & $41.7 \%$ & $52.6 \%$ & $13.0 \%$ \\
$\mathrm{~N}=$ & $\mathbf{9 8}$ & $\mathbf{6 0}$ & $\mathbf{3 8}$ & $\mathbf{1 , 9 6 5}$ \\
& Table 8. Willing to pay for a news “app" & \\
\hline & All & $\mathbf{1 8 - 2 4}$ & $25+$ & Other PEW \\
Yes & $15.9 \%$ & $12.5 \%$ & $20.0 \%$ & $1.0 \%$ \\
\hline
\end{tabular}




$\begin{array}{lllll}\mathrm{N}= & 44 & 24 & 20 & 2,251\end{array}$

\section{DISCUSSION}

For the combined college-aged group, there appears to be no difference when it comes to accessing information online, but there were significant differences in almost every question regarding additional online viewing behavior and connection to traditional media sources when compared to the Pew respondents. The results suggest that Selwyn [21] and Carr [7] were correct in that the effects are not able to be described in generational terms, but rather the relationship of net culture to college students, regardless of their age. It appears that the adoptive behavior of the student culture speaks the true social-cultural aspects of individuals whose day to day lives, patterns, and habits determine their participation. Again, Selwyn [28, p. 364] found that young adults' use of digital technologies were often varied and unspectacular, asserting that the term digital native "highlights a misplaced technological and biological determinism." Crain [8] also explained what could be these cultural phenomena as "groupiness" which would assist in the explanation of the similarity of the college students regardless of the diversity in their ages. This further suggests that additional segmentation may be needed to determine viewing behaviors and patterns with certainty, but the data clearly suggests that college students, regardless of age, seem to use mobile applications to access news more often than other populations.

\section{Observations}

It would be nice to know if these individuals regularly view the news. The questions deal with access and pay but we do not know anything about their viewing habits. They might only view news when it impacts them.

How are they accessing their local news - through social media, from friends, from family, radio, tv? There is so much free news online (even local) that most might have the idea that one should not have to pay extra for an "app" or any type of monthly fee.

The habit forming behavior suggested by Diddi and LaRose [10], which causes the population to seek out traditional forms of media as a source for news, appear to be replaced with new habits produced by news seekers with access to more advanced forms of media. In fact, college students overwhelmingly responded that they do not value news enough to pay a monthly $\$ 5$ subscription for it in the delivery mode of digital "apps" or online. In fact, roughly half of the respondents indicated that they have not downloaded a free "app" to obtain local news. When citing the types of information they access a mobile device were: check local weather reports; followed by, find local restaurants. Each of the following responses received almost the same percentage of responses equally: local sports updates/scores, coupons; and, information about local traffic or public transportation.

\section{LIMITATIONS AND FUTURE APPLICATIONS}

It is very common to hear the term "information overload" used to describe Internet searches, internal corporate communications, and social media. "Information overload," a term coined by Gross [12, p. 856] and popularized by Toffler [31], refers to the difficulty a person can have understanding an issue and making decisions that can be caused by the presence of too much information. It is a bombardment to the senses, causing confusion, distraction, disorientation and lack of responsiveness long before assessing the validity of the content or recognizing the risk of misinformation. The anxiety and frustration caused by the "information overload" can lead to a blind acceptance of all media news, or an outright rejection of all incoming news alerts, and/or a paralytic response akin to a collaborative shutdown in an information silo [3].

"Personalization" of our news and its sources will continue to play an important role in handling this digital information overload. Our use of filtering tools, such as rich site summaries (RSS), aggregate searches, newsgroups, email lists, blogs, online community feeds, and YouTube alerts, etc. [7] allow us to screen out the information we do not want by requesting packaged news to match our personal interests. Conversely, Carr [7] argues that "narrowcasting," also has hidden dangers that may present future dilemmas for the newsreader. Instead of editors 
and producers deciding what news is important, the user can access interactive web tools to gather only the material that he or she finds interesting giving an individual tremendous control over a personalized news flow. But with this empowerment, rejection of unlimited access to news worthy-current events and world headlines, may be overshadowed by the customization of limited daily alerts and highlights of specific topics, such as entertainment, sports, stock market reports, politics, etc. A common information term, the feedback loop, also applies and is cause for concern in that the more an individual seeks news personalization and becomes enamored with a subject; the greater the desire for more of the same information gradually excluding all others. Festinger [11] coined this concept of "selective avoidance" or "selective exposure" as a desire to produce consistency in our lives; but Carr [7, p. 109] argued that "commonsense logic suggests that we may be inclined to use these tools to narrow our horizons rather than expand them." Exploration of the positive and negative results of web news customization for both young and older adults, will increasingly be a topic of future interest and worth a further look.

When discussing the results with current college students, a pattern developed that suggests they are relying on a trusted community of discourse for their information such as social media "apps" rather than "trusted" media news "apps." Turkle [32, p. 295] argued that when we are overwhelmed by an influx of data, "we expect more from technology and less from each other," drawing us to digital media solutions that are convenient, responsive, and speedy so that we can move on to the latest news alerts or other pressing issues. Further development of the trusted advisor status and the relationship dynamics of obtaining this level in the social network among students, could assist in understanding knowledge transfer techniques that would give tools a greater level of credibility and understanding. This credibility and understanding among social networks, including and especially specific terms used in a community of discourse, should, in turn, increase tool utilization over time seeping into all age cohorts. Moreover, understanding the dynamics of a social network news distribution could have other benefits outside of simple consumption leading to dramatic changes in news production. Understanding and harnessing the power of a social network to produce "trusted" news could lead to additional insights into knowledge transfer, which is extremely important both in industry and academia.

\section{CONCLUSIONS}

It was expected that college-aged students were more likely than the overall population to use news "apps" as their main source of news over traditional news sources. While this population was expected to be engaged in the news it is uncertain whether they would purchase "apps" or gravitate toward those offered at no cost. Those that did gravitate indicated they would not pay for news "apps;" however, it is not clear whether they would view the news on free "apps." We need to further explore the results through a qualitative exploration to investigate if they are gathering their news from "trusted" sources on social media sites, the additional role culture plays in their viewing behavior, and the impact of "information overload" as a result of always being connected.

\section{REFERENCES}

1. Batteau, A. W. (2010). Technology and culture. Long Grove, IL: Waveland Press, Inc.

2. Bayne, S., \& Ross, J. (2007). The 'digital native' and 'digital immigrant': A dangerous opposition. Annual Conference of the Society for Research into Higher Education (Paper Presented), 1-6. Retrieved from: http://www.malts.ed.ac.uk/staff/sian/natives final.pdf

3. Borkovich, D. J. (2012). When corporations collide: Information overload. Issues in Information Systems, 13(2), 269-284.

4. Bostrom, R. P., \& Heinen, J. S. (1977). MIS Problems and failures: A sociotechnical perspective - Part I: The cause. MIS Quarterly, 1(3), 1977, 17-32.

5. Carr, N. G. (2003). IT doesn't matter. Harvard Business Review OnPoint, 3566, 41-49.

6. Carr, N. G. (2004). Does IT matter? Information technology and the corrosion of competitive advantage. Boston, MA: Harvard Business School Press.

7. Carr, N. G. (2010). The shallows: What the internet is doing to our brains. New York, NY: W. W. Norton \& Company, Inc.

8. Crain, C. (2008). How is the internet changing literary style? Steamboats Are Ruining Everything Blog. Retrieved from: www.steamthing.com/2008/06/how-is-the-inte.html. 
9. Dent, A. (2008). Are you a digital native? If you are over 22, you're an immigrant. Birmingham Post UK, 1, 20.

10. Diddi, A., \& LaRose, R. (2006). Getting Hooked on News: Uses and Gratifications and the Formation of News Habits Among College Students in an Internet Environment. Journal of Broadcasting \& Electronic Media, 50(2), 193-210.

11. Festinger, L. (1957). A theory of cognizant dissonance. Stanford, CA: Stanford University Press.

12. Gross, B. M. (1964). The managing of organizations: The administrative struggle. New York, NY: The Free Press.

13. Hall, E. T., \& Hall, M. R. (1990). Understanding cultural differences. Yarmouth, ME: Intercultural Press, Inc.

14. Hembrook, H., \& Gay, G. (2003). The laptop and the lecture: The effects of multitasking in learning environments. Journal of Computing in Highere Education, 15(1), 46-64.

15. Hofstede, G., Hofstede, G. J., \& Minkov, M. (2010). Cultures and organizations: Software of the mind. New York, NY: McGraw-Hill.

16. Kling, R. (1999). What is social informatics and why does it matter? D-Lib Magazine, 5(1). Retrieved from: http://www.dlib.org/dlib/january99/kling/01notes.html.

17. Kohut, A., Doherty, C., Dimock, M., \& Keeter, S. (2012). Trends in news consumption: 1991 - 2012, In changing news landscape, even television is vulnerable. Pew Research Center for the People and the Press, September 27, 2012. Retrieved from: http://www.people-press.org/files/legacy-pdf/2012\%20News\%20Consumption\%20Report.pdf

18. McLuhan, M., \& Lapham, L. H. (1994). Understanding media: The extensions of man. Cambridge, MA: MIT Press, Inc. (Originally published 1964)

19. Olmstead, K., Rosenstiel, T., \& Mitchell, A. (2011) Navigating News Online - Pew Research Center. Pew Research Center Publications. Retrieved from: http://pewresearch.org/pubs/1986/navigating-digital-news-environment-audience.

20. Parker, B., \& Plank, R. (2000). A Uses and Gratifications Perspective on the Internet as a New Information Source. American Business Review, 18(2), 43-50.

21. Perez-Carballo, J., \& Blaszczynski, C. (2011). Social media usage by business college students. Proceedings of the Academy of Information and Management Sciences (Paper Presented), 15(2), 5-8.

22. Perez-Carballo, J., \& Huarng, A. (2011). Attitudes of college students towards users and usability: A pilot study. Proceedings of the Academy of Information and Management Sciences (Paper Presented), 15(2), 9-13.

23. Petrides, L., McClelland, S., \& Nodine, T. (2004). Costs and benefits of the workaround: Inventive solution or costly alternative. The International Journal of Educational Management, 18(2/3), 100-108.

24. Postman, N. (1985). Amusing ourselves to death: Public discourse in the age of show business. New York, NY: Viking Press.

25. Postman, N. (1993). Technopoly: The surrender of culture to technology. New York, NY: Vintage Books.

26. Prensky, M. (2001). Digital natives, digital immigrants. On the Horizon, 9(5), 1-6. Retrieved from: http://www.marcprensky.com/writing/prensky

27. Purcell, K., Rainie, L., Rosenstiel, T., \& Mitchell, A. (2011). How mobile devices are changing community information environments. Pew American Life Project Report, March 14, 2011. Retrieved from: http://pewinternet.org/Reports/2011/Local-mobile-news.aspx

28. Selwyn, N. (2009). The digital native - myth and reality. Aslib Proceedings: New Information Perspectives, 61(4), 364-379.

29. Stroud, N. (2007). Media Use and Political Predispositions: Revisiting the Concept of Selective Exposure. Political Behavior, 30(3), 341-366.

30. Todd, D. M. (2013, April 19). Safety solutions local colleges are going beyond text and email alerts to warn students about emergencies on campus. Pittsburgh Post-Gazette, p. A-10. Retrieved from: http://search.proquest.com/docview/1328493003?accountid=28365

31. Toffler, A. (1970). Future shock. New York, NY: Random House.

32. Turkle, S. (2011). Alone together: Why we expect more from technology and less from each other. New York, NY: Basic Books. 